\title{
High-Temperature Deformation Behavior of Alpha Ti-5.6 mol\%Al Alloy
}

\author{
By Tsutomu Oomori*, Tatsuo Yoneyama** and Hiroshi Oikawa***
}

\begin{abstract}
Tensile tests were carried out on fine- and coarse-grained hcp Ti-5.6 mol\%Al alloy in the temperature range from $1000 \mathrm{~K}$ to $1150 \mathrm{~K}$ under the strain-rate range from $1.1 \times 10^{-6} \mathrm{~s}^{-1}$ to $1.7 \times 10^{-2} \mathrm{~s}^{-1}$ and the steady-state deformation characteristics were analyzed using the Dorn-type equation. Two stress ranges, other than the power-law breakdown, were recognized; the stress exponents were about 3.5 and 4.8 in the low and high stress ranges, respectively. The activation energy for creep was about $290 \mathrm{~kJ} / \mathrm{mol}$ in both stress ranges, which is significantly larger than that for diffusion. The transition condition between two stress ranges depends little on the deformation conditions. The grain size affected mainly on the numerical factor of the Dorn-type equation.
\end{abstract}

(Received February 3, 1988)

\begin{abstract}
Keywords: high temperature tensile test, hcp solid solution, steady-state deformation characteristics, alpha titanium-aluminum alloy, creep equation, stress dependence, temperature dependence, grain-size dependence
\end{abstract}

\section{Introduction}

Deformation characteristics at high temperature have systematically been studied on some simple solid solutions of cubic systems. ${ }^{(1)(2)}$. Alloys of the (fcc) Al-Mg system can be cited as typical examples, deformation behavior and the mechanisms of which are extensively analyzed, though there is still unsolved problems ${ }^{(3)}$. High-temperature deformation of bcc alloys has also been studied, though the extent is less than that done on fcc $\mathrm{Al}-\mathrm{Mg}$ alloys. The discrepancy in deformation characteristics between fcc Al-Mg alloys and bcc Fe-Mo alloys, which had been reported ${ }^{(4)}$, has recently been understood as only apparent one: alloys of both systems behave very similarly at high temperature $^{(5)(6)}$.

In simple solid solutions of the hcp system,

* Graduate Student, Tohoku University. Now with Technical Research Center, Nippon Yakin Kogyo Co. Ltd., Kawasaki 230, Japan.

** Graduate Student, Tohoku University. Now with Keihin Works, Asahi Glass Co. Ltd., Yokohama 230, Japan.

*** Department of Materials Science, Faculty of Engineerlng, Tohoku University, Sendai 980, Japan. however, little systematic study was reported on their high-temperature deformation characteristics. Alloys of the hcp system can be divided into two groups; one in which the value of $c / a$ is close to, or larger than, the ideal ratio, $\sqrt{8 / 3}$, the other in which $c / a$ is obviously less than the ideal one. Titanium is an example of the latter type metals, in which the primary slip system is of non-basal.

In this paper some experimental results obtained in an $\alpha \mathrm{Ti}-\mathrm{Al}$ solid solution at high temperatures are reported. The Ti-Al binary system is one of most basic systems in practical Ti-base alloys and also an interesting system from the point of fundamental view because of its large size misfit, $-0.072^{(7)}$. The present results will give a basis for discussing the effect of crystal system on deformation behavior of solid solutions at high temperature.

\section{Experimental Procedures}

\section{Material}

The material used was an arc-melted ingot of a Ti-5.62 mol\% (3.26 mass\%) Al alloy. Main impurities (in mass\%) were $\mathrm{Fe}: 0.013$, O: $0.113, \mathrm{~N}: 0.007, \mathrm{H}: 0.005$, and C: 0.009. The ingot $(\phi 145 \mathrm{~mm})$ was forged and hot-rolled to a 
Table 1 Heat treatment and the resulted grain-size of Ti-5Al.

\begin{tabular}{lcc}
\hline Designation & Heat treatment & $\begin{array}{c}\text { Grain size* } \\
(\mathrm{mm})\end{array}$ \\
\hline Ti-5Al (f) & $1150 \sim 1180 \mathrm{~K}, 25 \sim 14 \mathrm{ks}$ & $0.04 \sim 0.06$ \\
Ti-5Al (c) & $1330 \mathrm{~K}, 1.8 \mathrm{ks} \rightarrow 1150 \mathrm{~K}, 20 \mathrm{ks}$ & $0.8 \sim 1.5$ \\
\hline
\end{tabular}

* The grain size was measured by linear intercept method.

bar $(\phi 16 \mathrm{~mm})$, from which tensile specimens were machined. The dimensions of the gage part were $3.0 \sim 5.0 \mathrm{~mm}$ in diameter and $10 \sim 20 \mathrm{~mm}$ in length.

Two groups of specimens were prepared in respect of their grain size. An ordinary heattreatment made the grain size only about 0.05 $\mathrm{mm}$ as far as specimens were annealed in the $\alpha$ phase range alone, as in the case of pure (commercial) titanium ${ }^{(8)}$. These specimens will be denoted as the fine-grained alloy, Ti-5Al (f). When specimens were heated up slightly over the $\beta /(\alpha+\beta)$ transus for a relatively short duration, and then were annealed at the $\alpha$-phase temperature, the resulting grain-size became as large as about $1 \mathrm{~mm}$. These specimens will be denoted as the coarse-grained alloy, Ti-5Al (c). The condition of heat-treatments and the resulting grain-size are listed in Table 1.

\section{Tensile test}

The testing procedure was essentially the same as that reported in previous papers ${ }^{(8)(9)}$. Simple tensile tests were carried by a geardriven machine. The travelling speed of the cross-head ranged from $2.2 \times 10^{-8} \mathrm{~m} / \mathrm{s}$ to $1.33 \times 10^{-4} \mathrm{~m} / \mathrm{s}$.

The specimen was heated in a fused-silica tube by an infrared heating furnace. Temperature was measured by a Pt $/ \mathrm{Pt}-12.8 \% \mathrm{Rh}$ thermocouple, which contacted with the specimen at the center. Test temperature, which ranged from $1000 \mathrm{~K}$ to $1150 \mathrm{~K}$, was kept within $\pm 1 \mathrm{~K}$ of the set value during a test. The specimen was held at the test temperature for about $5 \mathrm{ks}$ in an argon atmosphere before starting a test.

\section{Correction of tensile curves}

Nominal (engineering) stress-nominal strain $\left(\sigma^{\prime}-\varepsilon^{\prime}\right)$ curves were converted to true stress-

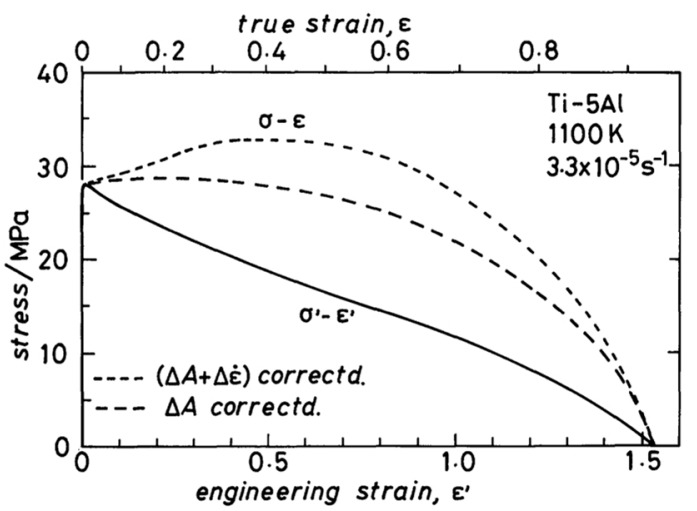

Fig. 1 A typical example of the correction of a stressstrain curve for the reduction in the cross-sectional area, $\Delta A$, and for the reduction in true strain-rate, $\Delta \dot{\varepsilon}$.

true strain $(\sigma-\varepsilon)$ curves corresponding to constant true-strain-rate condition using the following equations:

$$
\begin{aligned}
& \varepsilon=\ln \left(1+\varepsilon^{\prime}\right), \\
& \sigma=\sigma^{\prime}\left(1+\varepsilon^{\prime}\right)^{1+1 / n} .
\end{aligned}
$$

Here, $n$ is the stress exponent defined by

$$
\dot{\varepsilon}=A \sigma^{n} \text {, }
$$

where $\dot{\varepsilon}$ is the strain rate. The exponent in eq. (2), $1 / n$, is introduced to make the correction for the reduction in the true strain-rate in the present tests.

An example of the curve correction is shown in Fig. 1. The necessity of the correction cited above is obviously seen in the figure.

\section{Results and Discussion}

\section{Generals}

Typical stress-strain curves obtained are shown in Fig. 2. Under some experimental conditions "high-temperature yielding",(10) is observed. The stress increases with strain and reaches its maximum level and a (quasi-) plateau appears in most cases. Strain to rupture is around 1.0 in true strain except under severe conditions.

\section{Relation between $\dot{\varepsilon}$ and $\sigma_{\mathrm{s}}$}

Steady-state stress $\sigma_{s}$, or the maximum stress in some cases, are summarized in Table 2. The 


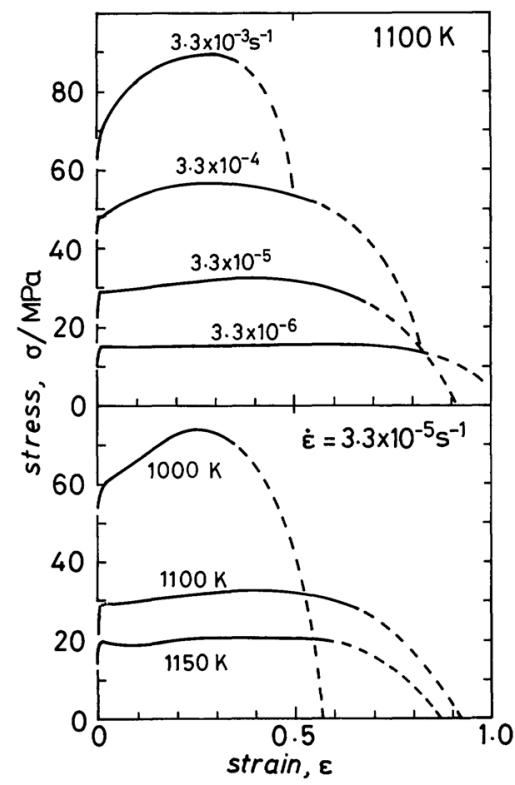

Fig. 2 Examples of true stress-true strain curves in Ti$5 \mathrm{Al}(\mathrm{f})$ at $1100 \mathrm{~K}(\mathrm{a})$ or with $3.3 \times 10^{-5} \mathrm{~s}^{-1}$ in strain-rate (b). effect of strain rate $\dot{\varepsilon}$ on $\sigma_{\mathrm{s}}$ is shown in Fig. 3, in which two regions of power-law relationship can be recognized. Power-law breakdown can also be notified at high strain-rates or high

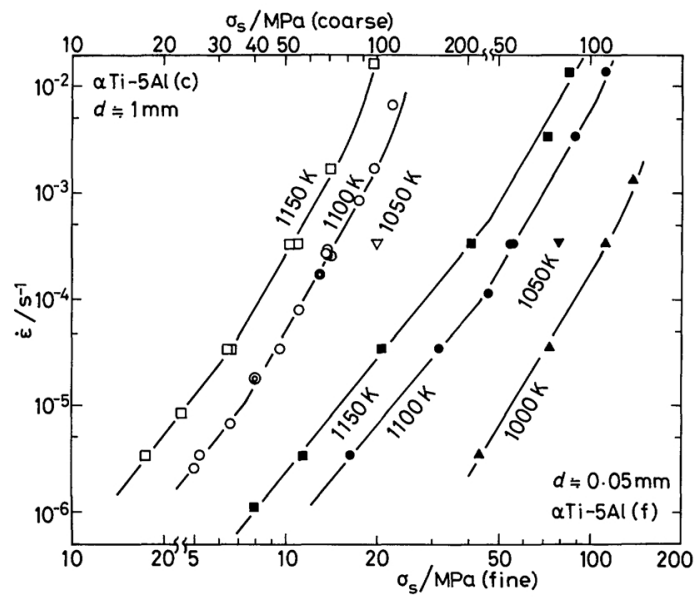

Fig. 3 Relation between strain-rate $\dot{\varepsilon}$ and steady-state stress $\sigma_{\mathrm{s}}$ in $\alpha \mathrm{Ti}-5.6 \mathrm{~mol} \% \mathrm{Al}$ alloy. Open marks: coarsegrained specimens, solid marks: fine-grained specimens.

Table 2 Deformation characteristics of Ti-5.6 mol\%Al alloy.

\begin{tabular}{|c|c|c|c|c|c|c|c|}
\hline \multicolumn{4}{|c|}{$\mathrm{Ti}-5 \mathrm{Al}(\mathrm{f})$} & \multicolumn{4}{|c|}{$\mathrm{Ti}-5 \mathrm{Al}(\mathrm{c})$} \\
\hline$\underset{(\mathrm{K})}{\text { Temp. }}$ & $\begin{array}{l}\text { Strain-rate } \\
\qquad\left(s^{-1}\right)\end{array}$ & $\begin{array}{c}\text { Steady-state } \\
\text { stress } \\
\text { (MPa) }\end{array}$ & Region* & $\begin{array}{c}\text { Temp. } \\
\text { (K) }\end{array}$ & $\begin{array}{l}\text { Strain-rate } \\
\left(\mathrm{s}^{-1}\right)\end{array}$ & $\begin{array}{c}\text { Steady-state } \\
\text { stress } \\
\text { (MPa) }\end{array}$ & Region \\
\hline \multirow[t]{3}{*}{1000} & $\begin{array}{l}1.33 \times 10^{-3} \\
3.3 \times 10^{-4}\end{array}$ & $\begin{array}{l}137 \\
112\end{array}$ & $\begin{array}{c}\text { PLB } \\
\mathrm{H}\end{array}$ & 1050 & $3.3 \times 10^{-4}$ & 99 & (H) \\
\hline & $3.3 \times 10^{-5}$ & 73 & $\mathrm{H}$ & \multirow[t]{10}{*}{1100} & $6.7 \times 10^{-3}$ & 108 & PLB \\
\hline & $3.3 \times 10^{-6}$ & 43 & $\mathrm{H} / \mathrm{M}$ & & $1.67 \times 10^{-3}$ & 98 & PLB \\
\hline 1050 & $3.3 \times 10^{-4}$ & 81 & (H) & & $\begin{array}{l}8.3 \times 10^{-4} \\
3.0 \times 10^{-4}\end{array}$ & $\begin{array}{l}87 \\
69\end{array}$ & $\begin{array}{c}\text { PLB } \\
\mathrm{H}\end{array}$ \\
\hline \multirow{6}{*}{1100} & $1.33 \times 10^{-2}$ & & PLB & & $\begin{array}{l}2.5 \times 10^{-4} \\
1.67 \times 10^{-4}\end{array}$ & $\begin{array}{l}71 ; 70 \\
65 ; 65\end{array}$ & $\begin{array}{l}\mathrm{H} \\
\mathrm{H}\end{array}$ \\
\hline & $3.3 \times 10^{-3}$ & 89 & H & & $8.8 \times 10^{-5}$ & $\begin{array}{c}05 ; 05 \\
55\end{array}$ & $\begin{array}{l}\mathbf{H} \\
\mathrm{H}\end{array}$ \\
\hline & $3.3 \times 10^{-4}$ & $56 ; 55$ & $\mathrm{H}$ & & $3.3 \times 10^{-5}$ & 48 & $\mathrm{H}$ \\
\hline & $1.11 \times 10^{-4}$ & 46 & $\mathrm{M} / \mathrm{H}$ & & $1.75 \times 10^{-5}$ & $41 ; 40$ & $\mathrm{H}$ \\
\hline & $3.3 \times 10^{-5}$ & 32 & M & & $6.7 \times 10^{-6}$ & 33 & $\mathbf{M}$ \\
\hline & $3.3 \times 10^{-6}$ & 16.5 & M & & $3.3 \times 10^{-6}$ & 26.4 & M \\
\hline & & & & & $2.5 \times 10^{-6}$ & 25.3 & M \\
\hline \multirow[t]{7}{*}{1150} & $1.33 \times 10^{-2}$ & 85 & $\mathrm{H}$ & & & & \\
\hline & $3.3 \times 10^{-3}$ & 69 & $\mathrm{H}$ & \multirow[t]{6}{*}{1150} & $1.67 \times 10^{-2}$ & 98 & PLB \\
\hline & $3.3 \times 10^{-4}$ & 41 & $\mathrm{H} / \mathrm{M}$ & & $1.67 \times 10^{-3}$ & 71 & $\mathbf{H}$ \\
\hline & $3.3 \times 10^{-5}$ & 20.6 & M & & $3.3 \times 10^{-4}$ & $55 ; 52$ & $\mathrm{H}$ \\
\hline & $3.3 \times 10^{-6}$ & 11.4 & M & & $3.3 \times 10^{-5}$ & $33 ; 33$ & $\mathrm{H} / \mathrm{M}$ \\
\hline & $1.11 \times 10^{-6}$ & 8.0 & M & & $8.3 \times 10^{-6}$ & 22.7 & $\mathbf{M}$ \\
\hline & & & & & $3.3 \times 10^{-6}$ & 17.4 & $\mathbf{M}$ \\
\hline
\end{tabular}

* PLB denotes the power-law breakdown. 
Table 3 Stress exponent, $n$, for steady-deformation of Ti-5Al.

\begin{tabular}{llcl}
\hline Alloy & Temp. & Region $\mathrm{R}$ & Region H \\
\hline Ti-5Al & $1000 \mathrm{~K}$ & - & $4.80 \pm 0.32(43 \sim 112)$ \\
(fine) & $1100 \mathrm{~K}$ & $3.42 \pm 0.03(16 \sim 46)$ & $4.97 \pm 0.09(55 \sim 89)$ \\
& $1150 \mathrm{~K}$ & $3.55 \pm 0.09(8 \sim 41)$ & $4.91 \pm 0.50(41 \sim 85)$ \\
\hline Ti-5Al & $1100 \mathrm{~K}$ & $3.53 \pm 0.48(25 \sim 33)$ & $5.05 \pm 0.15(40 \sim 69)$ \\
(coarse) & $1150 \mathrm{~K}$ & $3.63 \pm 0.09(17 \sim 33)$ & $4.98 \pm 0.22(33 \sim 71)$ \\
\hline & & $3.53 \pm 0.07$ & $4.95 \pm 0.12$ \\
\hline \hline
\end{tabular}

Numerical figures in parentheses represent the range of stress in $\mathrm{MPa}$.

Error limits refer to the standard deviation.

stresses.

In the low stress range the stress exponent $n$ in eq. (3) is about 3.5 (see Table 3 ) and in the high stress range it is about 5. These two regions are likely to correspond to regions $M$ and $\mathrm{H}$, respectively, in the $\dot{\varepsilon}-\sigma$ relationship obtained in fcc $\mathrm{Al}-\mathrm{Mg}$ alloys ${ }^{(11)(12)}$ and bcc $\mathrm{Fe}-$ Mo alloys ${ }^{(5)(6)}$.

\section{Effect of grain size}

It is obvious from Table 3 that little difference in $n$ can be recognized in each region under the present experimental conditions. The $\dot{\varepsilon}-\sigma$ curves of fine-grained and coarsegrained samples can be reduced to a single curve under the same condition, as shown in

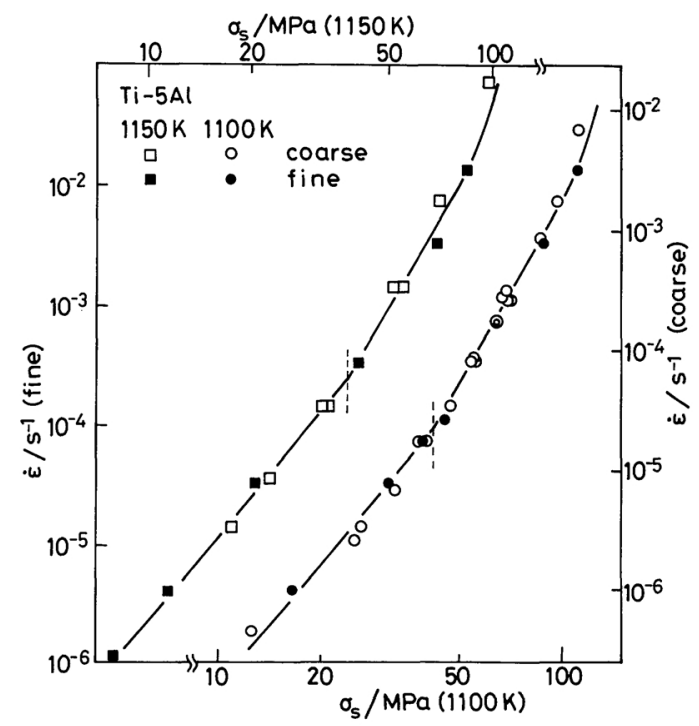

Fig. 4 Generalized relationship between $\dot{\varepsilon}$ and $\sigma$ in Ti$5 \mathrm{Al}$.
Fig. 4, when $\dot{\varepsilon}$ for coarse-grained samples $\dot{\varepsilon}(c)$ are multiplied by a factor 4.3 .

These results suggest that fundamental characteristics of high-temperature deformation in $\mathrm{Ti}-5.6 \mathrm{~mol} \% \mathrm{Al}$ alloy depend little on the grain size. This conclusion will become more evidently in the following sections.

\section{Effect of temperature}

Temperature dependence of $\sigma_{\mathrm{s}}$ at given strain-rates is shown in Fig. 5. The slope of lines in the figure corresponds roughly to $Q_{\mathrm{c}} / n$. It is obvious that the lines have similar slopes in each region.

The whole data are analyzed using a Dorntype equation, i.e.,

$$
\dot{\varepsilon}=A^{\prime}\left(\frac{G b}{k T}\right)\left(\frac{\sigma}{G}\right)^{n} \exp \left(-\frac{Q_{\mathrm{C}}}{R T}\right) .
$$

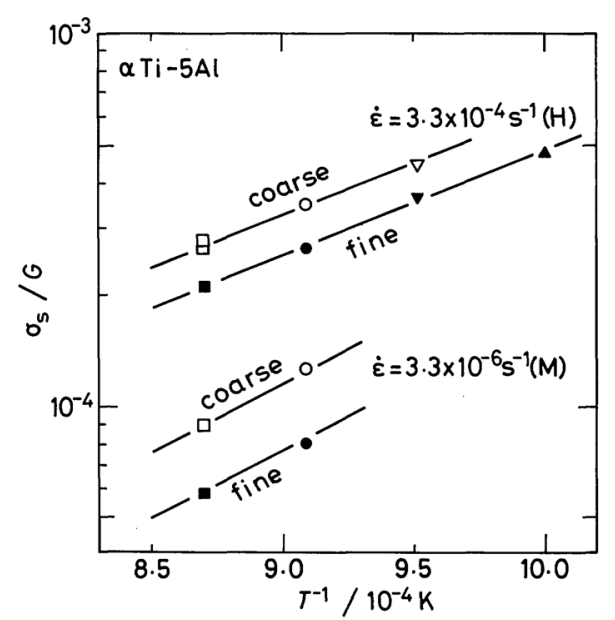

Fig. 5 Steady-state stress as a function of temperature in Ti-5Al. 
Table 4 Activation energy for creep, $Q_{\mathrm{C}}$ (in $\mathrm{kJ} / \mathrm{mol}$ ), or high-temperature steady-deformation, in Ti-5Al.

\begin{tabular}{ccc}
\hline \hline Alloy & Region M & Region $\mathrm{H}$ \\
\hline Ti-5Al (fine) & $287 \pm 8$ & $290 \pm 7$ \\
Ti-5Al (coarse) & $310 \pm 10$ & $306 \pm 16$ \\
\hline Overall & $297 \pm 13$ & $302 \pm 14$ \\
\hline \hline
\end{tabular}

* Error limits refer to the standard deviation.

Here, $G$ is the shear modulus, $b$ is the length of Burgers vector, $k$ is Boltzmann constant, $R$ is the gas constant, $T$ is the test temperature and $A^{\prime}, n$ (the stress exponent) and $Q_{\mathrm{C}}$ (the activation energy) are constants to be determined from the experiments. Shear modulus is estimated by the equation ${ }^{(8)}: G / \mathrm{Pa}=4.92 \times 10^{10}-$ $2.58 \times 10^{7} \mathrm{~T} / \mathrm{K}$.

The results are listed in Table 4, from which one may draw a conclusion that the activation energy of creep, or of high-temperature steady-deformation, in $\mathrm{Ti}-5.6 \mathrm{~mol} \% \mathrm{Al}$ alloy depends little on the deformation condition in the present experiments.

The value of $Q_{\mathrm{C}}$, about $290 \mathrm{~kJ} / \mathrm{mol}$, is significantly larger than that reported for the diffusion. The activation energy for self-diffusion of $\alpha$-titanium is reported to be about 170 $\mathrm{kJ} / \mathrm{mol}^{(13)}$ and that for the impurity diffusion of $\mathrm{Al}$ in $\alpha$-titanium to be about $160 \mathrm{~kJ} / \mathrm{mol}^{(14)}$. The activation energy for interdiffusion in $\alpha \mathrm{Ti}-\mathrm{Al}$ solid solutions are reported by some investigators to be smaller than these values. In most pure metals and simple alloys, $Q_{\mathrm{C}}$ is found to be close to $Q_{\mathrm{D}}{ }^{(1)}$, but the present case is obviously an exceptional one. The crystal system might affect the activation process, but no reasonable explanation of this significant difference between $Q_{\mathrm{C}}$ and $Q_{\mathrm{D}}$ is available at present.

\section{Creep equation}

Characteristics of steady-state deformation in alpha Ti-5.6 mol\% $\mathrm{Al}$ alloy can be expressed by the Dorn-type equation, eq. (4). All parameters are estimated from data on finegrained and coarse-grained specimens and listed in Table 5. The normalized relation between strain-rates and stresses is shown in Fig. 6.
Table 5 Parameters in the Dorn-type equation (eq. (4)) for steady-state deformation of Ti-5Al.

\begin{tabular}{lcc}
\hline Parameter & Region $\mathrm{M}$ & Region $\mathrm{H}$ \\
\hline$A^{\prime}$ (fine) & $7.7 \times 10^{11}$ & $2.1 \times 10^{15}$ \\
$A^{\prime}$ (coarse) & $1.80 \times 10^{11}$ & $0.49 \times 10^{15}$ \\
\hline$n$ & $3.5_{5}$ & $4.8_{1}$ \\
\hline$Q_{\mathrm{C}} / \mathrm{kJ} \cdot \mathrm{mol}^{-1}$ & & 288 \\
\hline \hline
\end{tabular}

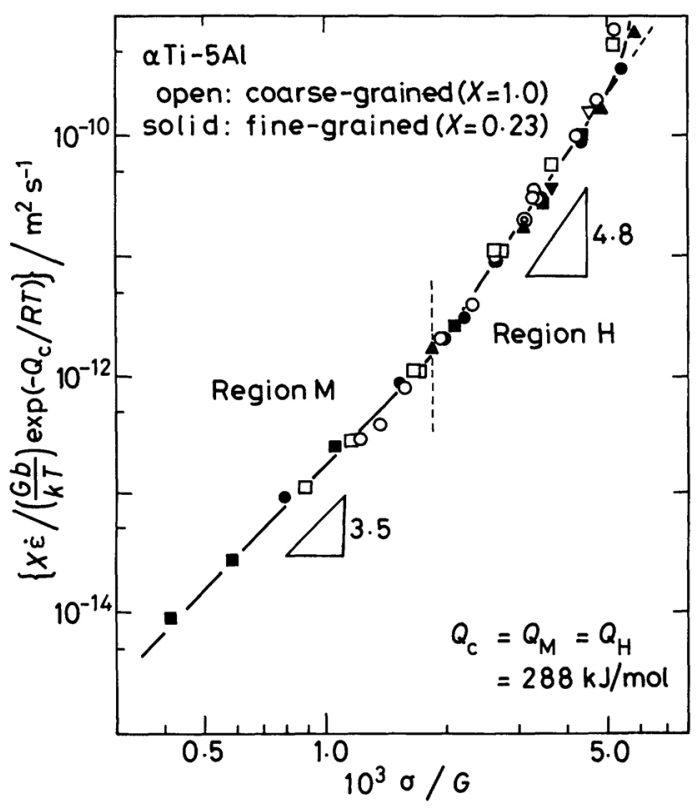

Fig. 6 Normalized strain-rate as a function of normalized stress in Ti-5Al.

The general trends of these characteristics obtained in hcp Ti-5.6 mol\%Al solid solution are very similar to those reported for powerlaw creep of fcc $\mathrm{Al}-\mathrm{Mg}^{(11)(12)}$ and also bcc Fe$\mathrm{Mo}^{(5)(6)}$ solid solutions. The value of $n$ is slightly smaller than 5 under high stresses (region $\mathrm{H}$ ) and slightly larger than 3 under intermediate stresses (region $\mathrm{M}$ ). Temperature dependence depends little on the stress level, $Q_{\mathrm{C}}^{\mathrm{M}} \approx Q_{\mathrm{C}}^{\mathrm{H}}$.

One notable difference between the present work and the previous ones is the absolute value of activation energy in respect to that for diffusion, $Q_{\mathrm{D}}$. In the previous work on fcc $\mathrm{Al}-$ $\mathrm{Mg}$ alloys and bcc Fe-Mo alloys, $Q_{\mathrm{C}}^{\mathrm{M}} \approx Q_{\mathrm{C}}^{\mathrm{H}} \approx$ $Q_{\mathrm{D}}$, while in the present work on hcp Ti-Al alloy, $Q_{\mathrm{C}}^{\mathrm{M}} \approx Q_{\mathrm{C}}^{\mathrm{H}}>Q_{\mathrm{D}}$.

The grain size affects greatly values of $A^{\prime}$. 
The degree of the influence depends little on the external deformation condition; $A^{\prime}$ (fine) $/ A^{\prime}($ coarse $) \approx 4$. A general discussion on the effect of grain size in hcp Ti-Al alloys will appear elsewhere ${ }^{(15)}$.

\section{Transition between regions $M$ and $H$}

In cubic solid solutions deformation in the power-law creep regime has been explained as follows $^{(3)}$. In region $M$ dislocations glide viscously because of the drag force arising from the solute (Cottrell) atmosphere around dislocations. Beyond a critical stress level, however, the solute atmosphere is broken and some dislocations can quickly move in the matrix where immobile solute atoms are distributed randomly. This behavior occurs in region $\mathrm{H}$, where the rate-controlling thermal activation process is a sort of recovery as in the case of pure metals.

A similar explanation may be applied to the present results. It is, however, necessary to establish firmly before applying this type of explanation that there is a term (or terms) which depends greatly on temperature other than the diffusion process.

Gliding characters of dislocations in hcp crystals, which are different from those in cubic crystals in some respect, can be one of candidates for the observed difference in the (apparent) activation energy. Even in pure hcp metals, the (apparent) activation energy, or strictly speaking, the observed temperature dependence, of high-temperature deformation depends greatly on the temperature range of the experiments ${ }^{(16)}$. No settled explanation on this matter has been given. Therefore, theoretical analyses of the present findings are a problem to be solved in future as a part of problems of the pecuriality observed in materials of the hcp crystal system.

\section{Transition stress}

The transition stress normalized by shear modulus $\sigma_{u} / G$ is little affected by the experimental condition; $\sigma / G=(1.69 \pm 0.11) \times 10^{-3}$ as seen in Fig. 6.

When one assumes that the transition between regions $M$ and $H$ occurs by the breakaway of the Cottrell (solute) atmosphere, the transition (effective shear) stress can be estimated by the following equation ${ }^{(17)}$, i.e.,

$$
\tau_{\mathrm{C}}=\frac{17}{2} \frac{\mathrm{W}}{\Omega b} N \text {. }
$$

Here, $\Omega$ is the atomic volume, $N$ is the solute concentration (in mole fraction) and $W$ is the elastic interaction parameter which can be evaluated by the equation,

$$
W=\frac{4}{3} \frac{(1+v)}{(1-v)} \text { Gber }^{3},
$$

where $v$ is the Poisson's ratio, $e$ is the size misfit parameter and $r$ is the radius of solvent atoms.

In Ti-5.62 mol\% $\mathrm{Al}$ alloy $\tau_{\mathrm{C}} / G$ is evaluated as about $20 \times 10^{-3}$, which is about 35 times as large as that observed in the experiment i.e., $\sigma_{u} / 3 G$. A similar difference between theoretical and observed values has also been reported in cubic solid solutions. These results suggest the necessity of some quantitative refinement, though the original estimation is qualitatively correct. Effect of $N$ on $\sigma_{u}$ will be discussed elsewhere in more detail ${ }^{(18)}$.

\section{Summary}

High-temperature deformation in the power-law creep regime of polycrystalline hcp $\mathrm{Ti}-5.6 \mathrm{~mol} \% \mathrm{Al}$ solid solution reveals the following steady-state characteristics.

(1) Two stress ranges, other than the socalled power-law breakdown, can be recognized.

In the low stress range, which corresponds to region $\mathrm{M}$ in $\mathrm{Al}-\mathrm{Mg}$ and $\mathrm{Fe}-\mathrm{Mo}$ alloys, the stress exponent $n$ is about 3.5 and high-temperature yielding can frequently be observed on the ordinary stress-strain recordings clearly. In the high stress range, which corresponds to region $\mathrm{H}$ in alloys of cubic crystal systems, $n$ is about 4.8 .

(2) The transition stress between regions $M$ and $\mathrm{H}$, which corresponds to the upper transition stress in cubic alloys $\sigma_{u}$, depends little on the deformation condition as far as it is normalized by shear modulus.

The absolute value of $\sigma_{\mathrm{u}} / 3 G$ obtained in the experiments is only about $1 / 30$ of the theoreti- 
cal value based on the Cottrell model. This discrepancy between observed and theoretical values for the atmosphere breakaway is similar to that observed in other alloys of cubic crystal systems.

(3) The relation between stress and strainrate in steady-state deformation can be represented by a Dorn-type equation.

Grain size affects almost solely the numerical factor $A^{\prime}$. Other parameters are little affected by grain size. The activation energies in two regions are close to one another, but obviously larger than that for the diffusion.

\section{Acknowledgments}

The material used was donated by Sumitomo Metal Ind. Mr. M.X. Cui (now with the Northeastern Institute of Heavy Machines, Tsitsihar, China) and Mr. K. Nishimura (now with Nippon Telephon and Telegram Co.) assisted some experiments in an initial phase of this investigation. The work was supported in part by the Grant-in-Aid of the Ministry of Education, Science and Culture, Japan (No. 59550429).

\section{REFERENCES}

(1) O. D. Sherby and P. M. Burke: Prog. Mater. Sci., 13 (1968), 325.
(2) S. Takeuchi and A. S. Argon: J. Mater. Sci., 11 (1976), 1542.

(3) H. Oikawa and T. G. Langdon: Creep Behaviour of Crystalline Solids, eds. B. Wilshire \& R. W. Evans, Pineridge Press, Swansea, (1985), p. 33-82.

(4) H. Oikawa: Creep and Fracture of Engineering Materials and Structures, eds. B. Wilshire \& D. R. J. Owen, Pineridge Press, Swansea, (1984), p. 89-101.

(5) H. Oikawa \& S. Nanba: Trans. Iron Steel Inst. Jpn., 27 (1987), 402.

(6) S. Nanba \& H. Oikawa: Mater. Sci. Eng., in press.

(7) H. W. King: J. Mater. Sci., 1 (1966), 79.

(8) M. X. Cui and H. Oikawa: Nippon Kinzoku Gakkaishi (J. Jpn. Inst. Metals), 49 (1985), 195.

(9) H. Oikawa, K. Nishimura \& M. X. Cui: Scr. Metall., 19 (1985), 825.

(10) R. Horiuchi, H. Yoshinaga \& Y. Hama: Nippon Kinzoku Gakkai-shi (J. Jpn. Inst. Met.), 29 (1965), 85.

(11) H. Oikawa, K. Honda \& S. Ito: Mater. Sci. Eng., 64 (1984), 237.

(12) H. Oikawa, H. Sato \& K. Maruyama: Mater. Sci. Eng., 75 (1985), 21.

(13) F. Dyment: Titanium-80, eds. H. Kimura \& O. Izumi, TMS-AIME, New York, (1980), p. 519.

(14) J. Räisanen, A. Anttila \& J. Keinonen: J. Appl. Phys., 57 (1985), 613.

(15) H. Oikawa, K. Sasaki, A. Sagara \& K. Maruyama: to be published.

(16) H. Siethoff \& K. Ahlborn: Z. Metallk., 76 (1985), 627.

(17) A. H. Cottrell: Dislocations and Plastic Flow in Crystals, Oxford Univ. Press, Oxford, (1953), p. 136.

(18) H. Oikawa and T. Oomori: to be published. 